\title{
ANALYTICAL MODEL FOR PASSING SIGHT DISTANCE DESIGN CRITERIA OF TWO-LANE ROADS IN SRI LANKA
}

\author{
W. K. Mampearachchi ${ }^{1}$, S. R. Masakorala ${ }^{2}$ \\ ${ }^{1}$ Professor of Civil Engineering \\ Department of Civil Engineering \\ University of Moratuwa, Sri Lanka \\ wk.mampearachchi@gmail.com \\ ${ }^{2}$ Postgraduate student \\ Department of Civil Engineering \\ University of Moratuwa, Sri Lanka \\ rajamalimasakorala@yahoo.com
}

\begin{abstract}
For a safe overtaking manoeuvre on two-lane highways, drivers need a sufficient sight distance along the roadway, but it depends on the traffic environment. To provide an adequate Passing Sight Distance (PSD), a number of models have been proposed since the initial model introduced by American Association of State Highways and Transport Officials (AASHTO) in 1954. It is a current design practice in Sri Lanka as well, however, not validated for local traffic conditions. This paper will present an alternative PSD model and an evaluation of AASHTO model for national highway design. Experiment was based on GPS data collection. In conclusion, PSD demand was satisfied by AASHTO PSD under mix traffic conditions, but not the safety concerns for speeds greater than $80 \mathrm{~km} / \mathrm{h}$, while alternative model successful for all speeds.
\end{abstract}

Keywords: GPS, design criteria, reliability, AASHTO, passenger cars

\section{Introduction}

Percentage of passing zones on two-lane highways indicate Level of Service (LOS) of that particular highway according to the Highway Capacity Manual (HCM). Generally, capacity measures; Percent Time Spent Following (PTSF) and Average Travel Speed (ATS) depend on the freedom of overtaking manoeuvres. To facilitate such passing opportunities legally using opposing traffic lane, there should be a sufficient sight distance and sufficient length of passing zones. Early 1950s, American Association of State Highways Officials (AASHTO) presented an empirical model based on data gathered during 1938 to 1941 under traffic conditions in the United States. Since, the proposed model was modified appropriately by other countries according to their traffic conditions and statuary requirements as shown in Table 1.

Table 1. PSD requirement in several countries for $70 \mathrm{~km} / \mathrm{h}$ design speed.(Harwood et al, 2008)

\begin{tabular}{|l|l|}
\hline Country & PSD $(\mathrm{m})$ \\
\hline Australia & 520 \\
\hline UK & 410 \\
\hline Canada & 480 \\
\hline Germany & 500 \\
\hline Greece & 500 \\
\hline South Africa & 490 \\
\hline USA & 482 \\
Sri Lanka & 482 \\
\hline
\end{tabular}

Development of PSD models could be identified as either actual field data obtained (Valkenburg and Micheal, 1971; Hassan et al., 1996; Harwood et al., 2008; Chandra and Shukla, 2012) or computer simulation programs (Ahmad and Papelis, 2001; Faraha, and Toledo, 2010; Kohoury and Hobeika, 2007) within past 70 years of introducing AASHTO PSD model. However, the basis of this research was a field data collection using a GPS data logger on selected national highways in Sri Lanka. 
Current PSD criteria for national two-lane road design are still based on the AASHTO Green Book. However, the model has not been validated for local traffic conditions. Since introducing AASHTO model in 1954, the road infrastructure, traffic regulations and vehicle performance have been improved to a significant extent. Therefore, there is a necessity of assessing AASHTO PSD design criteria for national highway designs mainly as a safety requirement. This research presented a new analytical model to calculate design PSD for national two-lane highway network and evaluation of adequacy of using AASHTO PSD criteria for design purposes in terms of safety.

\subsection{AASHTO Model}

AASHTO model completely depended on the basic kinematic relationships and validated in 1958 (AASHTO, 2001). According to the field observations, single vehicle passing manoeuvres were idealized to a most frequent pattern based on five assumptions. Also, the model reflected only ordinary passing manoeuvres of passenger cars with accelerated start (delayed start) and forced return (hurried return).

Conferring to the AASHTO model, before starting an overtaking manoeuvre, passing vehicle trails certain duration on decision-making and to react, showing a deceleration. Consequently, passing vehicle begins acceleration, called accelerative start and encroaches the opposing lane, when a sufficient sight distance is available to complete the manoeuvre. However, when passing vehicle on the opposing lane, it travels at uniform speed of $16 \mathrm{~km} / \mathrm{h}(10 \mathrm{mph})$ higher than impeding vehicle. Finally, passing vehicle returns to its lane immediately without disturbing opposing vehicle movement with a safe clearance.

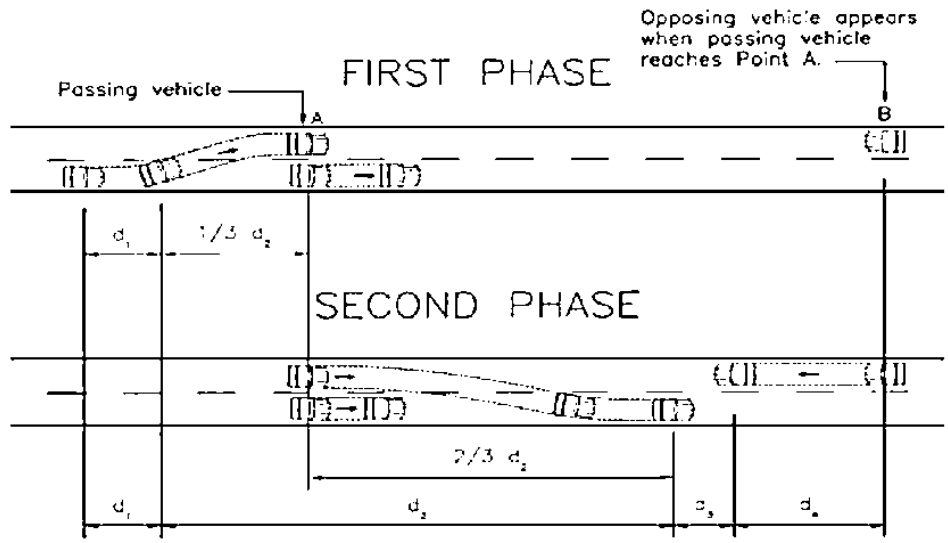

Figure 1. Passing manoeuvre given by AASHTO Green Book (AASHTO, 2001)

As Figure 1, total PSD required to complete a safe manoeuvre is given by the summation of $d_{1}$, $\mathrm{d}_{2}, \mathrm{~d}_{3}$ and $\mathrm{d}_{4}$ components. Relationships proposed to calculate each distance are stated in the AASHTO Green Book for an idealized ordinary passing manoeuvre as below.

$d_{1}=0.278 t_{1}\left(v-m+\frac{a t_{1}}{2}\right)$,

$d_{2}=0.278 v t_{2}$,

$d_{3}=$ Clearance distance,

$d_{4}=\frac{2}{3} d_{2}$,

$v$ : Average speed of passing vehicle $(\mathrm{km} / \mathrm{h})$,

$m$ : Speed differential between passed and passing vehicles $(\mathrm{km} / \mathrm{h})$,

$a$ : Average acceleration of passing vehicle $(\mathrm{km} / \mathrm{h} / \mathrm{s})$, and

$t_{1}$ : Time for initial manoeuvre (s),

$t_{2}$ : Time for passing vehicle on the left lane (s).

For initial manoeuvre, until passing vehicle encroaches the opposing lane, the distance $\left(d_{1}\right)$ depends on passing vehicle acceleration $(a)$, speed differential $(m)$, average passing vehicle speed $\left(V_{p}\right)$ and time taken for $\mathrm{d}_{1}$ distance $\left(t_{1}\right)$ as given in equation 1 . Passing vehicle speed was considered as slow 
down during trailing and has to be increased to start the overtaking manoeuvre. The ranges for $a$ and $t_{1}$ were estimated as $2.22 \mathrm{~km} / \mathrm{h} / \mathrm{s}$ to $2.43 \mathrm{~km} / \mathrm{h} / \mathrm{s}$ and $3.6 \mathrm{~s}$ to $4.5 \mathrm{~s}$ respectively, based on experimental data.

Subsequently, the distance traverse on the opposing lane $\left(d_{2}\right)$ was considered as the product of uniform speed of passing vehicle $\left(V_{p}\right)$ and time taken to travel $d_{2}$ distance $\left(t_{2}\right)$ as given in equation 2 . The observations for $t_{2}$ and $V_{p}$ was ranged from $9.3 \mathrm{~s}$ to $11.3 \mathrm{~s}$ and $48 \mathrm{~km} / \mathrm{h}$ to $113 \mathrm{~km} / \mathrm{h}$ respectively.

However, the clearance between passing and opposing vehicles at the end of passing manoeuvre $\left(d_{3}\right)$ was proposed after a several research done by AASHTO to find the safe clearance distance for stopping sight distance calculations. The model has selected the clearance values within $30-90 \mathrm{~m}$ range for design speed ranges from $50-110 \mathrm{~km} / \mathrm{h}$. (Exhibit 3-5 and 3-6, AASHTO, 2001).

Thereafter, the distance travelled by opposing vehicle during $t_{2},\left(d_{4}\right)$ was only two third $(2 / 3)$ of $d_{2}$, instead of the total distance to make the model conservative and allow terminating manoeuvre while proceeding. Finally, the minimum criteria have given for $85^{\text {th }}$ percentile of posted highway speeds.

\subsection{Other models}

Later research by Valkenburg and Mecheal (1971) addressed difficulties of completing passing manoeuvres without crossing no passing zones in short passing zone concept. Further, authors proposed that the return could be either forced return or voluntary return relative to the passing vehicle position from the point of no return. This point of no return was defined as the point which to continue and complete the passing manoeuvre is easier and safer thereafter than to apply brakes and return to its lane.

Glennon's critical passing model (1988) centred on the critical point concept, which placed when completed and incompleted passing manoeuvres taking equal distances. This model permitted parameters such as clearance between passing and passed vehicles and passing and opposing vehicles at the end of the manoeuvre and perception reaction time. All these parameters were explicit to $1 \mathrm{~s}$ to allow variations with passing vehicle speed while AASHTO model including only passing and opposing vehicles clearance separately. In contrast, Jenkins and Rilett calculated clearance distances using a simulation program, but results were not varied with passing vehicle speeds. However, space between passing and passed vehicles and passing and opposing vehicles at the end of the manoeuvre were stated as normal distributions with $23.5 \mathrm{~m}$ and $47.5 \mathrm{~m}$ mean and $12.19 \mathrm{~m}$ and $19.25 \mathrm{~m}$ standard deviation respectively.

In addition, speed differentials were varied accordingly passing vehicle speed instead of constant in AASHTO model, as $13-19 \mathrm{~km} / \mathrm{h}(8-12 \mathrm{mph})$ for higher to lower passing vehicle speeds respectively. Later models reflected on this method to avoid unnecessarily long PSD (Weaver and Glennon, 1969; Glennon, 1988; Hassan et al., 1996; Harwood et al., 2008).

$P S D=2 V_{d}\left(2+\frac{16-\Delta_{c}}{m}\right)$

$\Delta_{c}=16+m\left\{\frac{(2 m+32)}{\left(2 V_{d}-m\right)}-\left[\frac{V_{d}(2 m+32)}{2\left(2 V_{d}-m\right)}\right]^{1 / 2}\right\}$,

$V_{d}:$ Design speed (mph),

$m$ : Speed differential,

$\Delta_{c}:$ Relative position of front bumpers of passing and passed vehicles at critical point $(f t)$.

Most importantly, the Glennon model considered the influence of passing and passed vehicles lengths and group of values were presented according to the vehicle categories. Results clearly illustrated that the variation of PSD demand for increasing vehicle length was greater than for passenger cars and the rate of increasing of PSD demand was higher than for passenger cars.

Khoury and Hobeika replaced Glennon model with an analytical model using Monte Carlo simulation. Descriptive statistics of critical point and PSD along with Gama distribution at 95\% and 99\% confidence level were given $213.65 \mathrm{~m}$ and $215.32 \mathrm{~m}$ means and $9.99 \mathrm{~m}$ and $9.45 \mathrm{~m}$ standard deviations respectively. Further, the study proposed the minimum PSD which tended to grow with increasing values of parameters such as passing vehicle speed, clearance distances, perception-reaction time and vehicle lengths, while speed differentials effecting negatively. Further, the reliability index based on parameter distributions showed that the AASHTO model was more reliable for $80 \mathrm{~km} / \mathrm{h}$ speed, among Monte Calro model, MUTCD (Manual of Uniform Traffic Control Devices), Glennon model and AASHTO model. 
Table 2. A summary of design PSD proposed by different models

\begin{tabular}{|c|c|c|c|c|c|}
\hline \multirow{3}{*}{ Model } & \multicolumn{5}{|c|}{ Speeds $(\mathrm{km} / \mathrm{h})$} \\
\hline & 48 & 64 & 80 & 96 & 112 \\
\hline & \multicolumn{5}{|c|}{ PSD (m) } \\
\hline AASHTO (1954) & 332 & 448 & 559 & 650 & 756 \\
\hline Weaver and Glennon (1969) & - & - & 346 & 451 & 556 \\
\hline Glennon (1988) - Passenger cars & - & 204 & 253 & 301 & 347 \\
\hline Glennon (1988) - $110 \mathrm{ft}$ truck & - & 259 & 329 & 402 & 472 \\
\hline Hassan et al. (1996) & 143 & 216 & 243 & 439 & 656 \\
\hline Harwood et al. (2008) & 335 & 457 & 579 & 707 & 829 \\
\hline
\end{tabular}

\section{Methodology}

The methodology was consisted with two main parts as following,

1. Experimental method - GPS data collection of passing manoeuvres in the field.

2. Theoretical method - Analytical model derivation based on the typical trend observed.

The data collection was done on A and B class two-lane highways, with lanes wider than $3.6 \mathrm{~m}$. Almost similar conditions such as pavement conditions and availability of shoulders were selected to identify typical overtaking patterns. Dry weather conditions were considered, due to wet pavements reduce the overtaking safety and frequency. Field data collection was continued from October to December, during off-peak hours (09:00 - 15:00) as to observe more passing events under low traffic volume near posted speed limits. Mainly horizontal and vertical curves were avoided as they obstruct the sight distance. Design speed of roads was $70 \mathrm{~km} / \mathrm{h}$. But, posted speeds varied from $50 \mathrm{~km} / \mathrm{h}$ for town areas up to $70 \mathrm{~km} / \mathrm{h}$ for other areas. Parameters required to gather by this data collection were as follows.

a) Patterns of passing manoeuvres,

b) Speeds of passing, passed and opposing vehicles,

c) Acceleration/deceleration of passing vehicle,

d) Speed variations during passing manoeuvre,

e) Time required to complete a passing manoeuvre,

f) Distance travelled by passing vehicle for a complete manoeuvre,

g) Passed vehicle categories.

Two test vehicles categorized as passenger cars were used as passing vehicle. All passed vehicles were recorded manually and traversed paths were tracked using a GPS data logger. Then, GPS data previewed by Q-Travel software gave speed variations and coordinates of traversed path (latitude, longitude and altitude) accurately at $0.2 \mathrm{~s}$ intervals in tabular format.

\section{Data Analysis}

The observed passing manoeuvres were classified according to its start and finish as flying start, accelerative start (delayed start), volunteer return and forced return (hurried return) (Valkenberg and Micheal, 1971). A passing manoeuvre typically consists of above combination of starting and finishing scenarios as shown in Figure 2.

\section{Flying start and volunteer return (flying pass)}

It was difficult to identify without record of visual observations. When passing vehicle observed both a slow moving vehicle and clear opposing lane with long PSD, passing vehicle can make overtaking without reducing speed. As enough clearance distance is available, return of passing vehicle is not required immediately. Therefore, the clearance distances will be higher as shown in Figure 2(a). As a result of that PSD and marking distance would be longer than the usual.

\section{Flying start and forced return (hurried return)}

Though, it is same as the flying pass at the beginning, due to a sudden obstruction to the manoeuvre on the opposing lane, passing zone is not enough for a volunteer return and passing vehicle 
should return to previous lane immediately. Such cases will show higher passing vehicle speeds initially, but a deceleration at the end (Fig. 2(b)).

\section{Accelerative start (delayed start) and volunteer return}

Before starting manoeuvre, passing vehicle takes a few seconds to make decision of overtaking, whereas, passing vehicle reaches the passed vehicle speed. (Fig. 2(c)) Thus, the passing vehicle starts acceleration from a far below speed. However, though passing vehicle delayed to start, when enough gap is available to finish manoeuvre, it returns freely without reducing speed or cutting off passed vehicle.
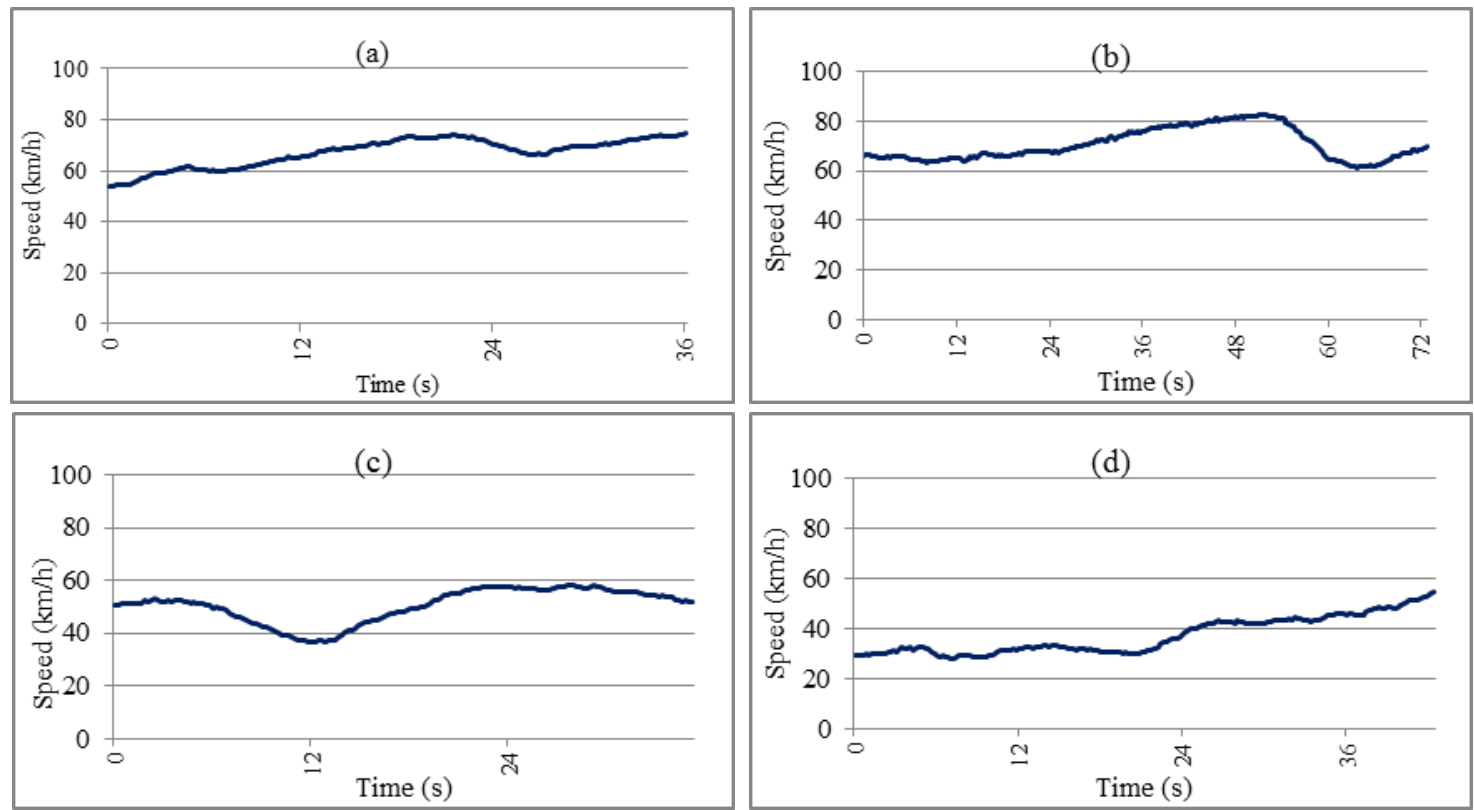

Figure 2. V-T diagrams of different passing manoeuvres (a) Flying start and volunteer return (b) Flying start and Forced return (c) Accelerative start and forced return (d) Accelerative start and volunteer return

\section{Accelerative start and forced return}

Completion of the manoeuvre occurs within a short time due to oncoming vehicle appears nearby. But, frequently passing vehicle trails long time before starting acceleration and needs to finish manoeuvre immediately as shown in Figure 2(d). Therefore, required PSD is minimized in this case.

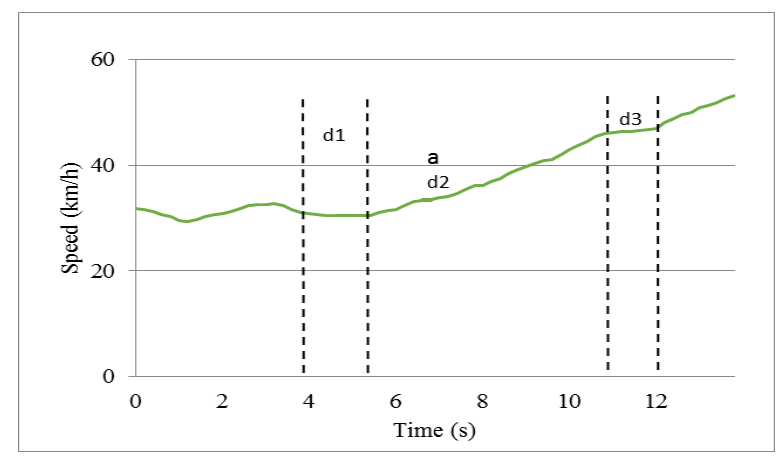

Figure 3. Typical passing manoeuvre observed in the field

Three major steps of a typical passing manoeuvre were identified as trailing distance $\left(\mathrm{d}_{1}\right)$, acceleration distance $\left(d_{2}\right)$ and distance to return and relax in the flow $\left(d_{3}\right)$ as in Figure 3 . Figure 4 outlines relative vehicle positions of an overtaking manoeuvre. Parameters such as speeds, speed differentials, accelerations were estimated based on GPS data. For example, passing vehicle speed $\left(V_{p}\right)$ was the maximum speed achieved after acceleration and passed vehicle speed $\left(V_{i}\right)$ was the minimum speed shown before acceleration. The average acceleration (a) was considered as the time taken for speed differential. 
Initial manoeuvre

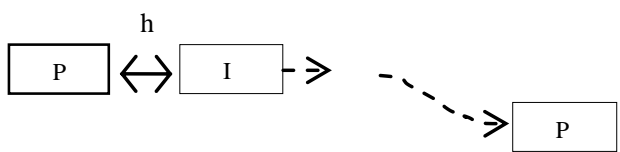

Acceleration end

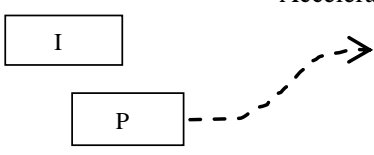

Acceleration begins

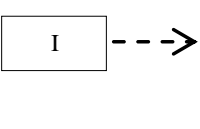

Acceleration

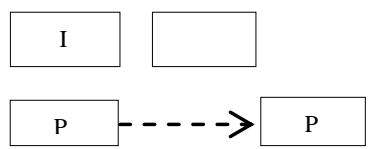

End manoeuvre

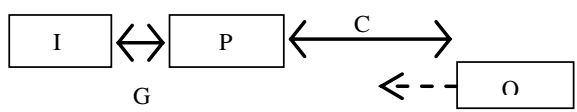

Figure 4. Conceptual diagram of a typical passing manoeuvre

\subsection{Analytical model}

Using kinematic relationships, a new analytical model for passenger cars was derived based on the typical passing manoeuvre. Six assumptions were made and justified based on empirical data analysis.

1. Passing vehicle travels at uniform speed $\left(V_{i}\right)$ equal to passed vehicle speed $\left(V_{i}\right)$ during perception reaction time after making decision to start acceleration and initial manoeuvre time $\left(t_{1}\right)$ was taken as $2.5 \mathrm{~s}$.

2. Speed differentials were within $16-12 \mathrm{~km} / \mathrm{h}$ for $30-80 \mathrm{~km} / \mathrm{h}$ speed range.

3. Passed vehicle travels at uniform speed $\left(V_{i}\right)$ throughout the passing manoeuvre.

4. Average vehicle acceleration (a) of passing vehicle depended on vehicle performance.

5. Passing vehicle travels $3 \mathrm{~s}$ after the acceleration at passing vehicle speed $\left(V_{p}\right)$, which is achieved at the end of acceleration.

6. Opposing vehicle travels at the equal speed of the passing vehicle $\left(V_{p}\right)$.
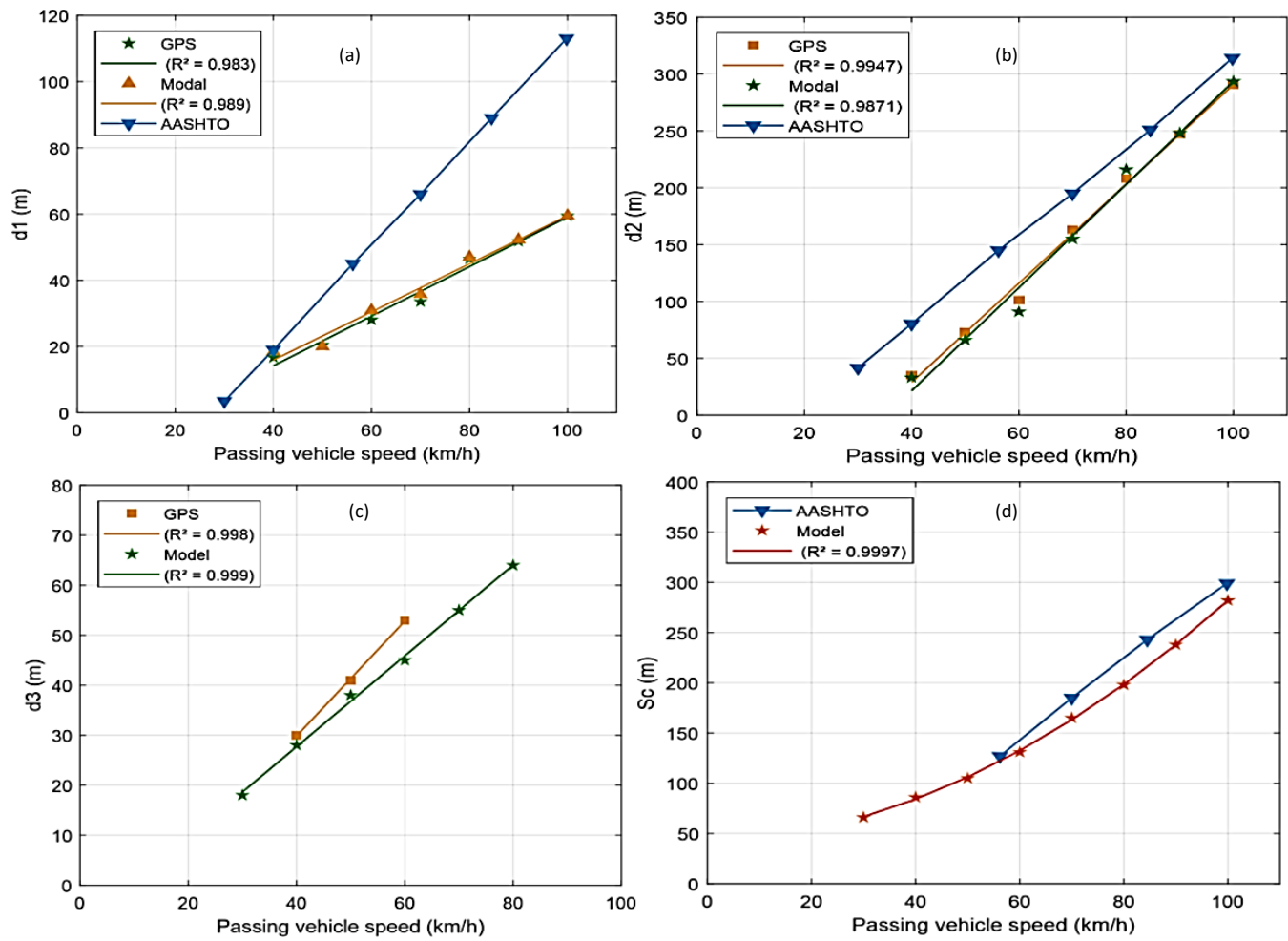

Figure 5. Comparison of (a) Initial manoeuvre $\left(\mathrm{d}_{1}\right)$ validation, (b) Accelerative distance $\left(\mathrm{d}_{2}\right)$ validation,

(c) Actual end manoeuvre $\left(\mathrm{d}_{3}\right)$ with assumed $3 \mathrm{~s}(\mathrm{~d})$ Critical sight distance $\left(\mathrm{S}_{\mathrm{c}}\right)$, with AASHTO

Following assumptions, each step of the manoeuvre was taken into a mathematical model as given below. 


\section{Initial manoeuvre $\left(d_{1}\right)$}

The initial distance which travelled by passing vehicle during perception reaction time $\left(\mathrm{t}_{1}\right)$ was expressed as following equation 6 according to the assumption 1 .

$\mathrm{d}_{1}=\mathrm{V}_{\mathrm{i}} \mathrm{t}_{1}$,

$\mathrm{t}_{1}=2.5 \mathrm{~s}$,

$\mathrm{V}_{\mathrm{i}}=\mathrm{V}_{\mathrm{p}}=\mathrm{V}_{\mathrm{d}}-\mathrm{m}$

$\mathrm{V}_{\mathrm{d}}$ : Design speed of highway and

$\mathrm{m}$ : Speed differential.

Equation 6 modified for the design speed of highway as given in equation 7. The maximum impeding vehicle speed was taken as the difference of design speed and speed differentials.

$\mathrm{d}_{1}=0.694\left(\mathrm{~V}_{\mathrm{d}}-\mathrm{m}\right)$.

\section{Acceleration distance $\left(d_{2}\right)$}

Equation for passing vehicle movement during acceleration $\left(\mathrm{t}_{2}\right)$ was articulated as following equation 8 . Acceleration time $t_{2}$ can vary based on the vehicle performance. (Assumption 4 )

$\mathrm{d}_{2}=0.5\left(\mathrm{~V}_{\mathrm{i}}+\mathrm{V}_{\mathrm{p}}\right) \mathrm{t}_{2}$,

$\mathrm{t}_{2}=\frac{\mathrm{m}}{\mathrm{a}}$

$\mathrm{m}$ : Speed differential,

a : Acceleration of passing vehicle.

By substituting in equation 8 , following equation 9 was derived for the design speed.

$\mathrm{d}_{2}=0.139\left(2 \mathrm{~V}_{\mathrm{d}}-\mathrm{m}\right) \frac{\mathrm{m}}{\mathrm{a}}$.

\section{Critical Sight Distance $\left(S_{c}\right)$}

After acceleration, passing vehicle needs the total traverse of passing and opposing vehicle during $t_{3}$ and safe clearance between passing and opposing vehicle at the end of manoeuvre as shown in Figure 4. This was defined as the critical sight distance, Sc. Further, according to the assumption 6, relative speed of the passing vehicle was twice the absolute passing vehicle speed as given in equation 10 .

$\mathrm{S}_{\mathrm{c}}=2 \mathrm{~V}_{\mathrm{p}} \mathrm{t}_{3}+\mathrm{C}$,

$\mathrm{t}_{3}=3 \mathrm{~s}$

C : Clearance distance between passing and opposing vehicles.

End manoeuvre time, $3 \mathrm{~s}$ was an average value derived empirically. By substituting in equation 10, $\mathrm{S}_{\mathrm{c}}$ was derived for design speed as given in equation 11

$\mathrm{S}_{\mathrm{c}}=1.67 \mathrm{~V}_{\mathrm{d}}+\mathrm{C}$.

Then, the total PSD was simply given by the summation of Equation 7, $9 \& 11$ as equation 12 .

$\operatorname{PSD}=\mathrm{d}_{1}+\mathrm{d}_{2}+\mathrm{S}_{\mathrm{c}}$

\subsection{Model validation}

The new PSD model was validated using empirical data, to check the reliability for actual scenario and to compare AASHTO criteria. The each step of the model was compared with the AASHTO model and actual demand. For initial manoeuvre $\left(\mathrm{d}_{1}\right)$, both new model and actual demand (GPS) gave similar results showing the accuracy of assumptions. Initial acceleration or deceleration rates were within $0-1$ $\mathrm{km} / \mathrm{h} / \mathrm{s}$ range for $\mathrm{t}_{1}$. However, they were not significant as presented by AASHTO model. Therefore, AASHTO $\mathrm{d}_{1}$ overlapped around $40 \mathrm{~km} / \mathrm{h}$ and continuously digress thereafter as given in Figure 5(a). Similarly, traverse during acceleration, $\mathrm{d}_{2}$ was compared with AASHTO $\mathrm{d}_{2}$ and new model. Trends of GPS and new model were very closely related, but not with AASHTO PSD. (Fig. 5(b)) 


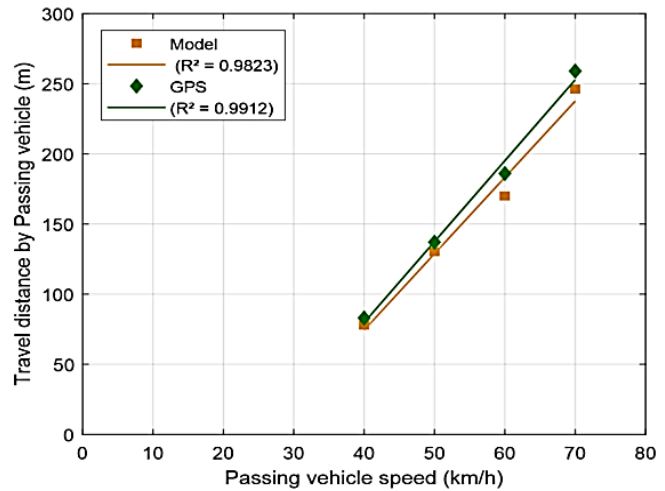

Figure 6. Total travel distance by passing vehicle

Under later part of new model presented two analysis of distance travelled during assumed $t_{3}$ equal to $3 \mathrm{~s}$ (Fig. 5(c)) and critical sight distance (Fig. 5(d)). The point of taking $3 \mathrm{~s}$, which was the average time spent by passing vehicles to reappear and relax on its lane, was to assess the accuracy of assumption 5. But, results were not closely related to the actual traverse of passing vehicle as the clearance distance could not be identified separately in the field. However, the critical sight distance of the new model did not exactly represent the AASHTO model, the summation of $\mathrm{d}_{3}$ and $\mathrm{d}_{4}$ components.

Finally, the total travel distance by passing vehicle given by GPS and new model were compared as explain in Figure 6. They develop similarly with increasing passing vehicle speed. Therefore, the proposed model could be suggested to forecast PSD requirement for given set of parameters successfully subjected to six assumptions.

\subsection{PSD calculations}

Parameters were assigned to analytical model to calculate PSD for the design speed based on field data analysis as given in Table 3. Then the summation of calculated $d_{1}, d_{2}$ and $S_{c}$ using equation 2,4 and 6 resulted total PSD, which were significantly lower than the AASHTO PSD.

Table 3. Proposed PSD based on the selected empirical values for analytical model

\begin{tabular}{|c|c|c|c|c|c|c|c|c|}
\hline \multirow{2}{*}{$\begin{array}{l}\mathrm{V}_{\mathrm{d}} \\
(\mathrm{km} / \mathrm{h})\end{array}$} & \multirow[t]{2}{*}{$\mathrm{a}(\mathrm{km} / \mathrm{h} / \mathrm{s})$} & \multirow{2}{*}{$\begin{array}{l}\text { M } \\
(\mathrm{km} / \mathrm{h})\end{array}$} & \multirow{2}{*}{$\begin{array}{l}\mathrm{C} \\
(\mathrm{m})\end{array}$} & \multicolumn{5}{|c|}{ PSD (m) } \\
\hline & & & & $\mathrm{d}_{1}$ & $\mathrm{~d}_{2}$ & $S_{c}$ & Total & AASHTO \\
\hline 30 & 3.5 & 16 & 30 & 10 & 28 & 80 & 118 & 200 \\
\hline 40 & 3 & 15 & 30 & 17 & 45 & 97 & 159 & 266 \\
\hline 50 & 2.5 & 14 & 30 & 25 & 67 & 114 & 205 & 341 \\
\hline 60 & 2 & 13 & 40 & 33 & 97 & 140 & 269 & 407 \\
\hline 70 & 1.5 & 12 & 55 & 40 & 142 & 172 & 354 & 482 \\
\hline 80 & 1 & 11 & 70 & 48 & 228 & 204 & 479 & 538 \\
\hline 90 & 0.5 & 10 & 80 & 56 & 473 & 230 & 758 & 613 \\
\hline
\end{tabular}

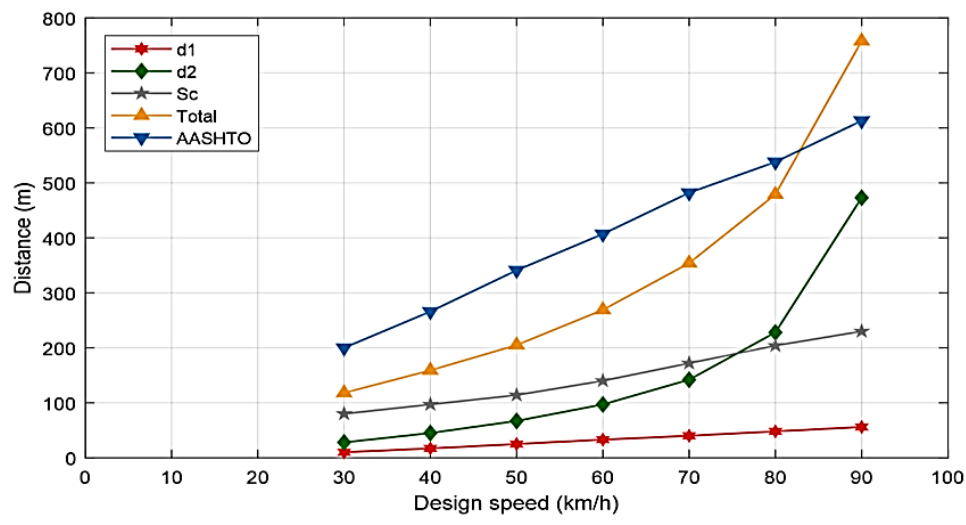

Figure 7. Proposed PSD for different design speeds 
Figure 7 clearly shows that design speeds up to $80 \mathrm{~km} / \mathrm{h}$ AASHTO model has given greater values than new model including all safety factors, as higher influence given by acceleration distance, $\mathrm{d}_{2}$. Further, at $90 \mathrm{~km} / \mathrm{h}$ speed, the new model $\mathrm{d}_{2}$ exceeded the AASHTO total PSD as well.

\subsection{Safety index $(\beta)$}

However, the reliability of proposed model and AASHTO model was needed to assess to decide which model is safer under actual demand. Following safety index method in equation 13 was introduced by Cornell in 1969, to compare network reliability under actual demand distribution (Khoury and Hobeika, 2007). Table 4 shows calculated indices for two models and actual demand.

$\beta=\frac{\mu_{\mathrm{s}}-\mu_{\mathrm{d}}}{\sqrt{\sigma_{\mathrm{s}}{ }^{2}+\sigma_{\mathrm{d}}^{2}}}$,

$\mu_{s}, \sigma s$ : Mean and standard deviation of provided PSD by AASHTO and new model, $\mu_{\mathrm{d}}, \sigma_{\mathrm{d}}$ : Mean and standard deviation of PSD demand on the considered highway.

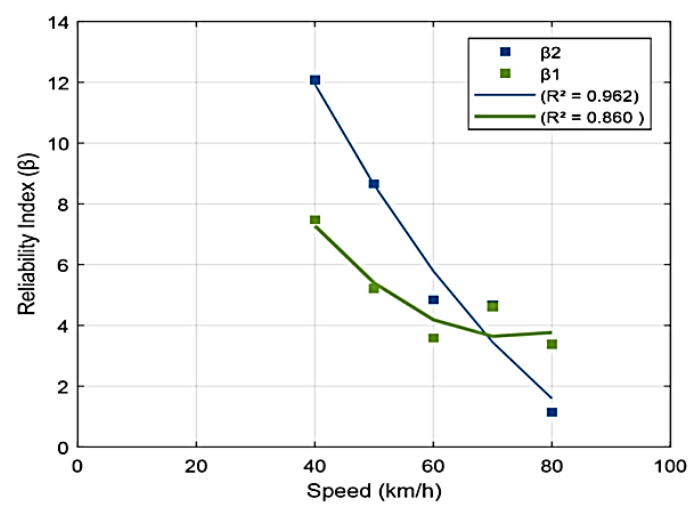

Figure 8. Comparison of AASHTO and new model

As shown in Figure 8, reliability of AASHTO model indicates higher decline at higher design speeds $\left(\beta_{2}<1\right.$ beyond $80 \mathrm{~km} / \mathrm{h}$ ) while polynomial trend of new model comes to a minimum around $70 \mathrm{~km} / \mathrm{h}$ for given vehicle mix on the national two-lane highway network.

\section{Discussion}

The observed passing manoeuvres were classified into four different categories based on accelerated start, flying start, forced return and voluntary return similarly by Valkenberg and Mecheal. However, the proposed PSD model was established for a typical passing manoeuvre, which was idealized based on six assumptions related to a frequent passing trend. Therefore, the results given by the proposed model were laid on the actual demand and gave more reliability for the final PSD values.

Table 4. Reliability indices for New model and AASHTO model

\begin{tabular}{|c|c|c|c|c|c|c|}
\hline \multirow{2}{*}{$\begin{array}{l}\text { Design speed } \\
(\mathrm{Vd})\end{array}$} & \multicolumn{2}{|c|}{ Actual Demand(a) } & \multirow{2}{*}{ New Model } & \multirow{2}{*}{$\beta 1(a)$} & \multirow{2}{*}{ AASHTO } & \multirow{2}{*}{$\beta 2(b)$} \\
\hline & Mean $(\mu)$ & Standard Deviation $(\sigma)$ & & & & \\
\hline 40 & 107.23 & 13.14 & 205 & & & \\
\hline 50 & 160.83 & 20.80 & 269 & 5.22 & 341 & 8.66 \\
\hline 60 & 204.55 & 41.81 & 354 & 3.59 & 407 & 4.84 \\
\hline 70 & 271.21 & 45.13 & 479 & 4.61 & 482 & 4.67 \\
\hline 80 & 426.05 & 98.39 & 758 & 3.38 & 538 & 1.14 \\
\hline
\end{tabular}

Note:

(a) PSD demand was considered for all types of passed vehicles.

(b) As the new model and AASHTO presented single values for each design speeds, standard deviations were taken as zero for all speeds $(\sigma s=0)$.

The speed differentials were within $12-18 \mathrm{~km} / \mathrm{h}$ range with $15 \mathrm{~km} / \mathrm{h}$ average verified assumption 2 , comparatively $16 \mathrm{~km} / \mathrm{h}$ in AASHTO model. But, the acceleration declined from $3.5 \mathrm{~km} / \mathrm{h} / \mathrm{s}$ to $0.5 \mathrm{~km} / \mathrm{h} / \mathrm{s}$ 
with increasing passing vehicle speed, which was contradictory with AASHTO model as it increased from $2.25 \mathrm{~km} / \mathrm{h} / \mathrm{s}$ to $2.41 \mathrm{~km} / \mathrm{h} / \mathrm{s}$.

The initial distance $\mathrm{d}_{1}$ in the AASHTO model, perception-reaction time and the trailing time until passing vehicle encroaches the opposing lane was taken into account but not explicit exactly. Despite of new model considered only perception reaction time of $2.5 \mathrm{~s}$ for all speeds, it was reasonable to explain initial manoeuvre with different travel trends. For instance, about $50 \%$ of vehicles had long trailing time while rarely observed flying passes and common accelerative starts without trailing time. However, initial travel time was not much significant in total PSD as it affected itself in decision-making and no any common indicator to identify to account initial time which can be led to unnecessary length of $\mathrm{d}_{1}$. Then perception-reaction time was considered as safe and sufficient for initial manoeuvre.

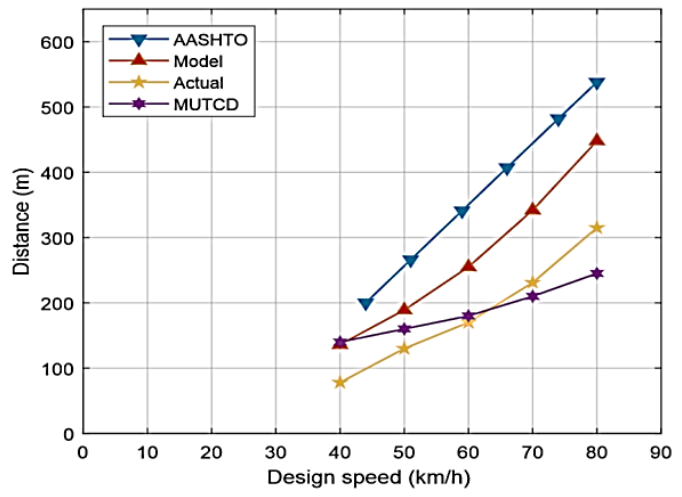

Figure 9. PSD for geometric design and marking

During passing manoeuvre, opposing vehicle was assumed same uniform speed as the passing vehicle and safe clearance between two vehicles at the manoeuvre completion. However, there were arguments on AASHTO clearance distance, that it was seamed insufficient for a safe manoeuvre. (Weaver and Glennon, 1969) In addition, time variable clearance (1s) was used by Glennon, Hassan et al., and Harwood et al. in their models. Throughout the end manoeuvre passing vehicle travelled at uniform speed and then trailed the front vehicle or accelerated to continue its travelling speed. (Assumption 3)

Figure 9 compares four PSD design criteria by different models. AASHTO trend is significantly higher than other models, while PSD proposed by MUTCD for marking purposes showing insufficient passing lengths to accommodate actual demands at higher design speeds. But, new model satisfy the field demand and exceed MUTCD beyond $40 \mathrm{~km} / \mathrm{h}$ speed. However, identified reasons to justify variances of AASHTO PSD model would be as below.

1) Vehicle performance has been increased than observed in 1950s.

2) Accelerative behaviour after initial manoeuvre has been completely disregarded by AASHTO model and considered acceleration rates during initial manoeuvre.

3) Time observed for passing vehicle on opposing lane is too long in AASHTO than in new model.

4) Differences of pavement conditions, road furniture and geometric design.

5) Traffic rules and regulations.

6) Errors of estimating parameters in new model as they depended on passing vehicle speed.

The required minimum PSD for a safe passing manoeuvre, given by new model was below the AASHTO recommended PSD and shown a non-linear relationship with greater increments at higher speeds beyond $80 \mathrm{~km} / \mathrm{h}$. However, according to the safety evaluation AASHTO PSD was more reliable than new model for speeds less than $70 \mathrm{~km} / \mathrm{h}$ and reliability degraded severely at higher speeds. But new model is conservative and safe for all speeds.

\section{Conclusions}

Following conclusions were made with the evaluation of AASHTO PSD design criteria under Sri Lankan traffic condition and the proposed alternative for the current practice.

- PSD demand on local two-lane highway network is far below than the AASHTO PSD for all speeds according to the field observations.

- Proposed new model presented lower values for speeds less than $80 \mathrm{~km} / \mathrm{h}$ and beyond that significantly increased than the AASHTO PSD. 
- However, in the safety analysis indicated that the reliability of AASHTO model was sharply reduced with increasing design speed while proposed model providing more reliable PSD for all speeds of actual demand.

Finally, adapting of AASHTO PSD criteria for local designs can be recommended and compatible with national traffic regulatory requirements in the context of safety but not conservative at lower speeds in maximizing capacity of two-lane highways. In addition, the present highway design guidelines for PSD, AASHTO is not encourage unsafe overtaking within the speed limits (max. $70 \mathrm{~km} / \mathrm{h}$ ), but the individual passing behaviour (e. g.: reckless driving behaviour and passed vehicle acceleration during overtaking) would cause to increase PSD demand and lead to increase the probability of occurring road accidents while overtaking.

\section{References}

1. A Policy on Geometric Design of Highways and Streets. (2004) $5^{\text {th }}$ edition. American Association of State Highway and Transportation Officials. Washington, DC.

2. Ahmad, O. and Papelis, Y.E. (2001) An autonomous driver model for the overtaking manoeuvre for use in microscopic traffic simulation. National Advanced Driving Simulator \& Simulation Centre, University of Iowa. Retrieved from: http://www.nads-sc.uiowa.edu

3. Chandra, S. and Shukla, S. (2012) Overtaking Behaviour on Divided Highways Under Mixed Traffic Conditions. Procedia - Social and Behavioral Sciences, 43 ( 2012 ) pp 313 - 322.

4. Faraha, H. and Toledo, T. (2010) Passing behaviour on two-lane highways. Transportation Research - Part F, 13(6) pp 355-364.

5. Glennon J.C. (1988) New and improved model of passing sight distance on two-lane highways, geometric design and operational effects, Transport Research Record 1195, pp 132-137.

6. GPS.gov, Retrieved from: http://www.gps.gov/systems/gps/

7. Harwood, D.W. Gilmore, D.K. Richard, K.R. Dunn, J.M. Sun, C. (2008) Passing Sight Distance Criteria. NCHRP report 605, Transportation Research Board, Washington, D.C.

8. Hassan, Y., Halem, A.E. and_Ease S.M. (1996) Passing sight distance on two-lane highways: review and revision. Transport Research. - A. 30(6), pp. 453-467.

9. Jenkins, J.M. and Rilett, L.R. (2006) Modelling the interaction between passenger cars and trucks. Report 473700-00015, Transportation Centre, Texas.

10. Khoury J.E. and Hobeika A. (2007) Incorporating uncertainty into the estimation of the passing sight distance requirements, Computer-Aided civil and infrastructure engineering.

11. Van Valkenburg, G.W. and Michael, H.L. (1971) Criteria for No Passing Zones. Highway Research Record 377, pp. 1-19.

12. Weaver, G.D. and Glennon, J.C. (1969) The passing manoeuvre as it relates to passing sight distance standards. Research Report 134, Texas Transportation Institute, Texas. 